\title{
MODEL CONSTRUCTION OF OPTION PRICING BASED ON FUZZY THEORY
}

\section{Shang-En Yu}

Department of Hospitality Management, Taiwan Shoufu University, No. 168, Nanshi Li, Madou Dist., Tainan City 72153, Taiwan, R.O.C.

\section{Ming-Yuan Leon Li}

Departmentt Accountancy \& Grad Inst Finance \& Banking, National ChengKung University, No. 1, University Road, Tainan City 701, Taiwan, R.O.C.

Kun-Huang Huarng

Department of International Trade, Feng Chia University, Taichung 40724, Taiwan, R.O.C.

Tsung-Hao Chen

Department of Business Administration, Shu-Te University, Yen Chau, Kaohsiung 82445, Taiwan, R.O.C.

\section{Chen-Yuan Chen}

Department and Graduate School of Computer Science, National Pingtung University of Education, No. 4-18, Ming Shen Rd., Pingtung 90003, Taiwan, R.O.C. Doctoral Program in Management, National Kaohsiung First University of Science and Technology, 2 Jhuoyue Rd. Nanzih, Kaohsiung 811, Taiwan, R.O.C. Global Earth Observation and Data Analysis Center (GEODAC), National Cheng Kung University, No. 1, Ta-Hsueh Road, Tainan 701, Taiwan, R.O.C., cyc@mail.npue.edu.tw

Follow this and additional works at: https://jmstt.ntou.edu.tw/journal

Part of the Business Analytics Commons

\section{Recommended Citation}

Yu, Shang-En; Li, Ming-Yuan Leon; Huarng, Kun-Huang; Chen, Tsung-Hao; and Chen, Chen-Yuan (2011) "MODEL CONSTRUCTION OF OPTION PRICING BASED ON FUZZY THEORY," Journal of Marine Science and Technology. Vol. 19: Iss. 5, Article 2. DOI: $10.51400 / 2709-6998.2160$

Available at: https://jmstt.ntou.edu.tw/journal/vol19/iss5/2

This Research Article is brought to you for free and open access by Journal of Marine Science and Technology. It has been accepted for inclusion in Journal of Marine Science and Technology by an authorized editor of Journal of Marine Science and Technology. 


\section{MODEL CONSTRUCTION OF OPTION PRICING BASED ON FUZZY THEORY}

\section{Acknowledgements}

The authors are appreciative of the financial support in the form of research grants to Dr. Chen-Yuan Chen from the National Science Council, Republic of China under Grant Nos. NSC 99-2628-E153-001 and NSC 100-2628-E153-001. The authors also wish to voice his appreciation for the kind assistance of Professor Chein-Shan Liu, Associate Editor of the Journal of Marine Science and Technology, and would also like to thank the anonymous reviewers for their constructive suggestions which have greatly aided in the improvement of this paper 


\title{
MODEL CONSTRUCTION OF OPTION PRICING BASED ON FUZZY THEORY
}

\author{
Shang-En Yu*, Ming-Yuan Leon Li**, Kun-Huang Huarng***, Tsung-Hao Chen****, \\ and Chen-Yuan Chen $* * * * * * * * * * *, * * * * * * *$
}

Key words: fuzzy set theory, option pricing, warrant, tree model, membership function.

\begin{abstract}
Option pricing is a tool that investors often use for the purpose of arbitrage or hedging. However, both the BlackScholes model and the CRR model can only provide a theoretical reference value. The volatility in the CRR model cannot always appear in the precise sense because the financial markets fluctuate from time to time. Hence, the fuzzy volatility is naturally to be considered. The main purpose of this paper is the application of fuzzy sets theory to the CRR model. It is expected that fuzzy volatility, instead of the crisp values conventionally used in the CRR model, can provide reasonable ranges and corresponding memberships for option prices, as a result of which, investors can interpret optimal value differently for different risk preferences. This paper shows a new method for option valuation using fuzzy set theory that is based on findings from earlier option valuation methods and from fuzzy membership function. In conclusion, the empirical evidence indicates the effectiveness of the proposed fuzzy model.
\end{abstract}

Paper submitted 10/30/09; revised 03/08/10; accepted 04/23/10. Author for correspondence: Chen-Yuan Chen (e-mail: cyc@mail.npue.edu.tw).

*Department of Hospitality Management, Taiwan Shoufu University, No. 168, Nanshi Li, Madou Dist., Tainan City 72153, Taiwan, R.O.C.

**Departmentt Accountancy \& Grad Inst Finance \& Banking, National ChengKung University, No. 1, University Road, Tainan City 701, Taiwan, R.O.C.

${ }^{* * *}$ Department of International Trade, Feng Chia University, Taichung 40724, Taiwan, R.O.C.

****Department of Business Administration, Shu-Te University, Yen Chau, Kaohsiung 82445, Taiwan, R.O.C.

*****Department and Graduate School of Computer Science, National Pingtung University of Education, No. 4-18, Ming Shen Rd., Pingtung 90003, Taiwan, R.O.C.

******Doctoral Program in Management, National Kaohsiung First University of Science and Technology, 2 Jhuoyue Rd. Nanzih, Kaohsiung 811, Taiwan, R.O.C.

*******Global Earth Observation and Data Analysis Center (GEODAC), National Cheng Kung University, No. 1, Ta-Hsueh Road, Tainan 701, Taiwan, R.O.C.

\section{INTRODUCTION}

Warrants supply investors with choices for financial leverage. When the price of the underlying asset rises, the owner of the warrant can buy the stocks at the specified price, the return will be a simple multiple of the purchased stocks. When the price of the underlying asset goes down, at most the premium is lost. If we can accurately predict the optimal range of an option price, investors can make a profit and hedge against losses from the derivatives.

The Black-Scholes model [3] or binomial tree option pricing model has been widely applied for computing the optimal warrant price. Volatility is assumed to be constant. However, as pointed out by Lauterbach and Schultz [51] and Hauser and Lauterbach [33], the volatility is the most controversial variable. Hence, many subsequent studies have focused on estimating the volatility, for example using historical data or the Parkinson method [66]. The different estimated volatilities certainly result in price variation. In this study, fuzzy set theory is applied to model the volatilities. It is expected that this method will replace the complex models used in the previous studies [6-28, 34-40, 47-50, 52-64, 68-76, 79-84, 88-92, 95-105].

Most recent studies of option pricing have focused on how to relax the assumptions made in the Black-Scholes model and CRR model [31]. These assumptions include: (1) the price fluctuation of the underlying asset must follow a log-normal distribution; (2) the short-term risk-free rate of interest is constant; and (3) the volatility of a stock remains constant. After relaxing these assumptions, we can set up new definitions. For example, we assumed that the price of an underlying asset follows the Poisson Jump-Diffusion Process or the Markov Process. The interest and volatility can also be random processes. In line with the focus in this paper on the volatility, we first discuss some literature regarding option pricing which is relevant to volatility. Fuzzy set theory as well as the binomial tree option pricing model are reviewed in the following section. In Section 3 fuzzy set theory is applied to the binomial tree option pricing model. Some empirical results from the fuzzy model are presented in Section 4. Conclusions to sum up the article are offered in Section 5. 


\section{LITERATURE REVIEW}

Hull and White [46] relaxed the assumption that the distribution of the price of underlying assets and volatility were constant. Wiggins [86], and Scott [67] let go of the assumption that the volatility was constant instead, assumed Stochastic-Volatility. Cox [30] introduced the concept of Constant-Elasticity-of-Variance for volatility. Amin [1] and Scott [67] considered the Jump-Diffusion processes of both stock prices and the volatility to be a random process. These models all endeavored to provide more accurate prices.

\section{Fuzzy Set Theory Revisited}

The origins of fuzzy sets theory track back to an article by Lotfi Zadeh [94] who stated that an element either belongs to a set or does not belong to a set at all in classical set theory. This type of true or false logic is commonly applied in financial applications. But, bi-value logic was not sufficiently comprehensive to deal with real world problems and presents a problem, because financial decisions are generally made under uncertainty. Consequently, an algebra called fuzzy sets was developed to deal with imprecise elements in our decision making processes, and is the formal body of theory that allows the treatment of practically all decisions in an uncertain environment [29]. Instead, it is more proper to represent items by a degree of membership indicating the degree of belongingness. Since then, this theory has been successfully applied in many problem domains, such as engineering, transportation, management and business.

Zadeh [94] extended the characteristic function to introduce the concept of fuzzy subset which is defined by its membership function that is viewed as an extension of characteristic function [87]. The fuzzy set concept deals with real observations through possibility. The membership function of a fuzzy set is introduced as follows. In traditional relations, we use 0 or 1 to represent the relationship. In fuzzy relations, we instead use a number between 0.0 and 1.0 to show the degree of relationship, as shown in Fig. 1. When the relationship is closer to 1, the relationship is stronger. On the other hand, when the relationship is closer to 0 , the relationship is weaker. In fuzzy set theory, the relationship is described through a membership function.

Two basis operators are applied to describe the relationships: an algebraic product and a minimum. The algebraic product is used to describe the propagation of the degree of membership ( $\mu$ ) from one time period to another. Let $R$ and $S$ be two fuzzy sets. Then

$$
\mu_{R \cdot S}=\mu_{R}(x) \cdot \mu_{S}(y)
$$

The minimum is used to calculate the intersection of the degree of membership $(\mu)$ of two different fuzzy sets; the maximum is used to represent the union

$$
\mu_{R \cap S}=\min \left(\mu_{R}(x), \mu_{S}(y)\right)
$$

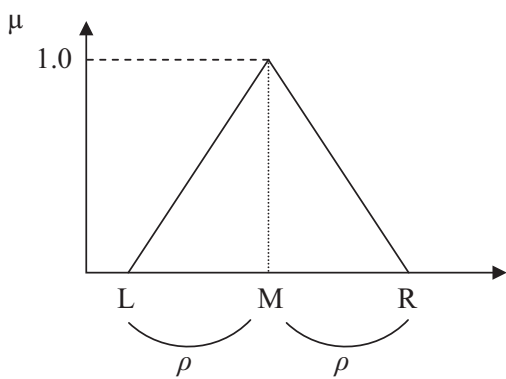

Fig. 1. A triangular fuzzy set.

$$
\mu_{R \cup S}=\max \left(\mu_{R}(x), \mu_{S}(y)\right)
$$

\section{Option Pricing Model}

Options play more and more important roles in the financial market as a widely applied in financial derivatives [62]. Generally, options are commonly valued with three methods. Black-Scholes option pricing formula [3] is also called BlackScholes model. The binomial option valuation method [31] and Monte-Carlo based methods [4, 29] are also utilized in the present work. Black and Scholes [3] made an important breakthrough by deriving a differential equation that the price of any derivative security dependent on a non-dividend paying stock must satisfy it. Concerning risk-neutral investors, the Black-Scholes pricing formula for a call option is [5]

$$
C_{0}=S_{0} N\left(d_{1}\right)-X e^{-r T} N\left(d_{2}\right)
$$

where

$$
d_{1}=\frac{\ln \left(S_{0} / X\right)+\left(r+\sigma^{2} / 2\right) T}{\sigma \sqrt{T}}, d_{2}=d_{1}-\sigma \sqrt{T}
$$

$C_{0}$ is the price of option; $S_{0}$ is the stock price; $N(d)$ is the probability that a random draw from a standard normal distribution which will be less than $d ; r$ is the annualized continuously compounded rate with the same maturity as the expiration of the option; $X$ is the exercise price; $T$ is the time of maturity and $\delta$ denotes the standard deviation of the annualized continuously compounded rate of return of the stock. Merton [65] extended the Black-Scholes model to dividendspaying stocks as

$$
C_{0}=S_{0} e^{-\delta T} N\left(d_{1}\right)-X e^{-r T} N\left(d_{2}\right)
$$

where

$$
d_{1}=\frac{\ln \left(S_{0} / X\right)+\left(r-\delta+\sigma^{2} / 2\right) T}{\sigma \sqrt{T}}, d_{2}=d_{1}-\sigma \sqrt{T}
$$

$\delta$ denotes the dividends paid out during the life-time of the 

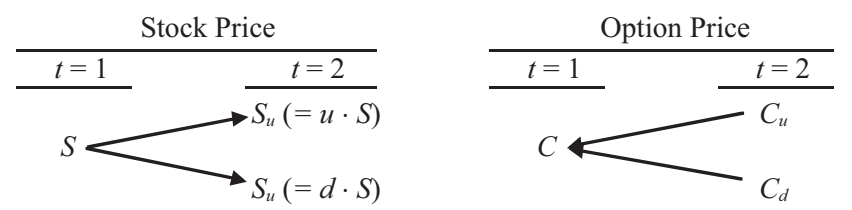

Fig. 2. Stock price movement in time $\Delta t$ under the binomial model.

option. The standard Black-Scholes model prices a European option on an asset follow a geometric Brownian motion. By using the modification of Black-Scholes formula [87], many methodologies for the option pricing have been proposed. Black-Merton-Schole developed a more general approach that derives a partial differential equation. Wang et al. [85] applied partial differential equation in pricing barrier options. Harrison and Kreps [32] developed the martingale approach to arbitrage thory that is the most general method for pricing of contingent claims [2].

\section{Binomial Tree Option Pricing Model}

Binomial options pricing model originated from Cox et al. [31], henceforth CRR model that has simple structure is widely applied in the financial market and is one of the basic options pricing methods [62]. First, the binomial tree option pricing model is introduced with a one-step example $(n=2$, where $n$ is the total period of time), including an option pricing model and its inference process. Other cases can be derived similarly as $n$ gets larger. Suppose the stock price at period $t=1, S$, is known. The one-step option pricing model can inference two possible stock prices (up and down movements) at some period $t=2$, as in Fig. 2. The corresponding call prices are calculated from the stock prices at $t=2$. Then, we can calculate back to the call price at $t=1$.

Let $P$ be the probability for $S$ to move up, and

$$
P=\frac{a-d}{u-d}
$$

where $a=e^{r \cdot \Delta t}$, the factor of discount; $r$ is the risk-free rate; $\Delta t$ is the length of one time period. Let

$$
u=e^{\sigma \cdot \sqrt{\Delta t}}
$$

represent the stock price after moving up, where $\sigma$ is the volatility of stock price. Let $d=1 / u$. Hence,

$$
d=e^{-\sigma \cdot \sqrt{\Delta t}}
$$

represents the stock price after moving down. Suppose $u>$ $a>d$.

From equation (4), we can calculate

$$
1-P=\frac{u-a}{u-d}
$$

As in Fig. 2, we define the following:

$$
\begin{aligned}
& S_{u}=u \cdot S \\
& S_{d}=d \cdot S
\end{aligned}
$$

where $S_{u}$ is the stock price for the next period (at $t=2$ ) when the stock price moves up; $S_{d}$ is the stock price for the next period (at $t=2$ ) when the stock price moves down.

Meanwhile, from the concept of the call price, let

$$
\begin{aligned}
& C_{u}=\max \left(0, S_{u}-K\right) \\
& C_{d}=\max \left(0, S_{d}-K\right)
\end{aligned}
$$

where $C_{u}$ is the call price at $t=2$, calculated from $S_{u}$; and $C_{d}$ is the call price at $t=2$, calculated from $S_{d} ; K$ is the exercised price.

Accordingly, we can get the following:

$$
C=\frac{(a-d) C_{u}+(u-a) C_{d}}{(u-d) a}
$$

Finally, substituting Eqs. (4) and (7) into Eq. (12), we obtain the call price at $t=1$, which is our goal

$$
C=\frac{P \cdot C_{u}+(1-P) \cdot C_{d}}{a}
$$

Similarly, we can calculate different stock prices for different total time periods $n$, and then calculate back to the call price at $t=1$.

\section{FUZZY BINOMIAL TREE OPTION PRICING MODEL}

Before set up the model, the following assumptions are allowed: (1) There is no transaction costs, no taxes, no restrictions on short sales, no arbitrage opportunities in the markets and assets are infinitely divisible. (2) The underlying asset does not pay dividends during the life of derivative. (3) The riskless rate of interest is constant and all maturities are the same. After combining binomial tree option pricing model and fuzzy theory, the binomial tree option pricing model is extended to fit a fuzzy binomial tree option pricing model. The results of inferences for fuzzy stock prices and fuzzy call prices are introduced in detailed by Yu et al. [93].

\section{The Process of Inference for Fuzzy Stock Prices}

Similar to the binomial tree option pricing model, we suppose that $S$ is known at $t=1$. After the fuzzification of $\sigma$ and $-\sigma$, the up and down movements $u$ and $d$ are replaced by $u u, u m$, and $u d$, and $d u, d m$, and $d d$, respectively. $u u, u m$, and $u d$ are three possibilities for the up movement under the largest, 


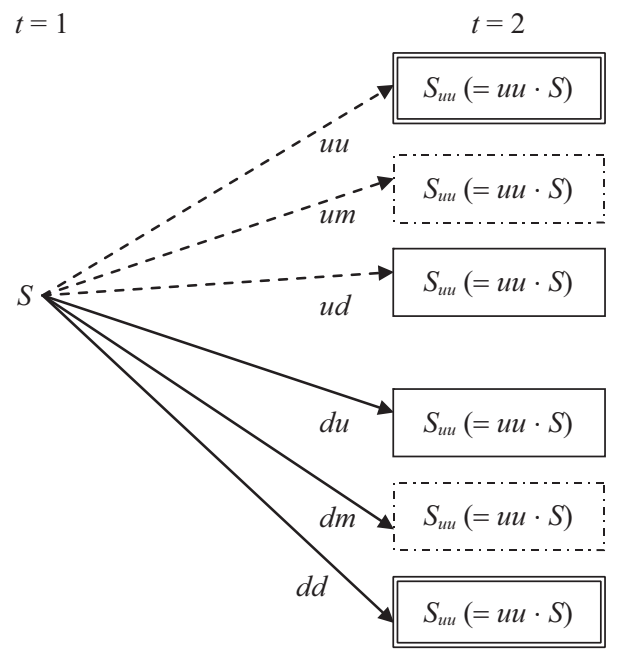

$\mu$

Fig. 3. Stock prices at $t=2$.

medium, and smallest volatility, respectively. $u u, u m$, and $u d$ can be defined as follows:

$$
u u=e^{(1+\rho) \cdot \sigma \cdot \sqrt{\Delta t}}, u m=e^{\sigma \cdot \sqrt{\Delta t}}, u d=e^{(1-\rho) \cdot \sigma \cdot \sqrt{\Delta t}}
$$

We also let $u u=\frac{1}{d d}, u m=\frac{1}{d m}, u d=\frac{1}{d u}$. Hence, $d u=$ $e^{-(1-\rho) \cdot \sigma \cdot \sqrt{\Delta t}}, d m=e^{-\sigma \cdot \sqrt{\Delta t}}, d d=e^{-(1+\rho) \cdot \sigma \cdot \sqrt{\Delta}}$.

Now, we can list all the possible stock prices through various combinations of $u u, u m$ and $u d$, and $d u, d m$ and $d d$.

All the stock prices at $t=n$ can be derived as follows:

$$
u u^{a} \cdot u m^{b} \cdot u d^{c} \cdot d u^{x} \cdot d m^{y} \cdot d d^{z} \cdot S
$$

where $a, b, c, x, y, z$ are integers and can be any combinations under the condition $a+b+c+x+y+z=n-1$; and $n$ is the total number of time periods.

Suppose there are $n$ time periods. The number of stock prices at $t=n$ are $6^{n-1}$.

For example, suppose for $t=2$ there are in total 6 stock prices. $a+b+c+x+y+z=n-1=1$. The stock prices at $t=2$ are derived as follows: when $a=1, b=c=x=y=z=0$, $S_{u u}=u u \cdot S$ with $\mu=0.1$. When $b=1, a=c=x=y=z=0$, $S_{u m}=u m \cdot S$ with $\mu=1.0$. When $c=1, a=b=x=y=z=0$, $S_{u d}=u d \cdot S$ with $\mu=0.1$. When $x=1, a=b=c=y=z=0$, $S_{d u}=d u \cdot S$ with $\mu=0.1$. When $y=1, a=b=c=x=z=0$, $S_{d m}=d m \cdot S$ with $\mu=1.0$. When $z=1, a=b=c=x=y=0$, $S_{d d}=d d \cdot S$ with $\mu=0.1$.

We have the above six equations for stock pricing: see Fig. 3. In this figure, the dash lines with arrows indicate upward movement from $t=1$ to $t=2$; while the solid lines indicate downward movement. The values in solid boxes $\left(S_{u d}\right.$ and $\left.S_{d u}\right)$ indicate the stock prices with the smallest volatilities at $t=2$; those in dashed boxes $\left(S_{u m}\right.$ and $\left.S_{d m}\right)$ indicate the stock prices with medium volatilities; and those in double boxes $\left(S_{u u}\right.$ and $\left.S_{d d}\right)$ indicate the stock prices with largest volatilities.

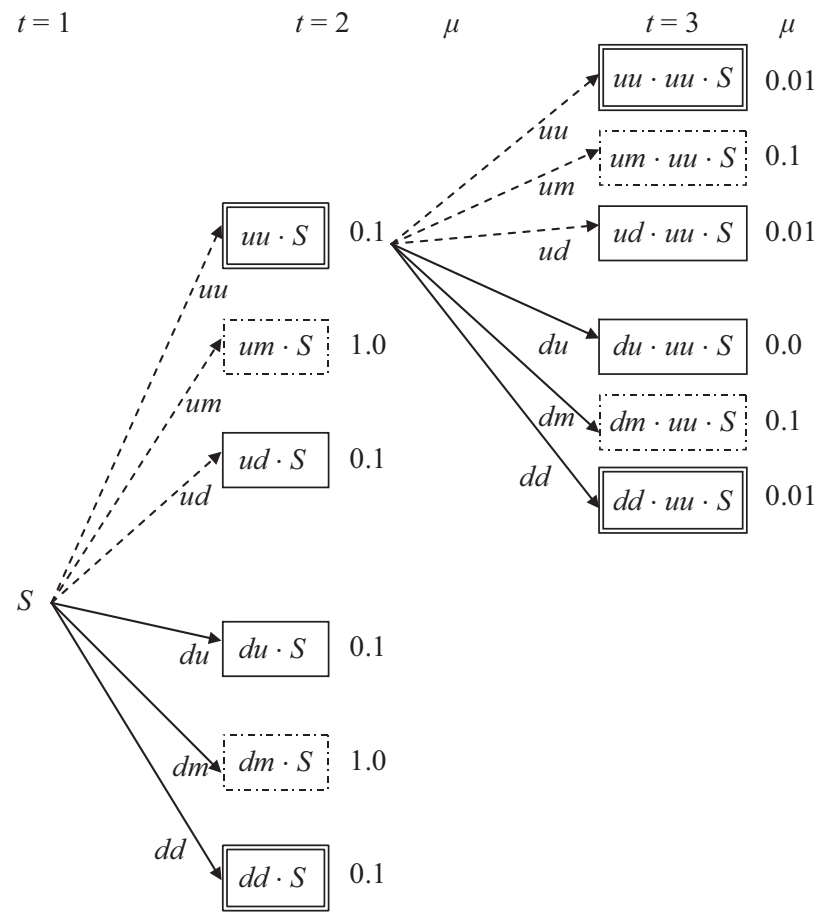

Fig. 4. Stock prices at $t=3$.

Let us take another example, $n=3$. There are $6^{n-1}=6^{2}=$ 36 stock prices. Only stock prices derived from $S_{u u}\left(=u u \cdot S_{u u}\right)$ are listed in Fig. 4. Similar to the case for $n=2$, there are six stock prices derived: $u u \cdot S_{u u}, u m \cdot S_{u u}, u d \cdot S_{u u}$ for the upward movement and $d u \cdot S_{u u}, d m \cdot S_{u u}, d d \cdot S_{u u}$ for the downward movement. Meanwhile, $\mu\left(u u \cdot S_{u u}\right)=0.1 \cdot 0.1=0.01, \mu(u m$. $\left.S_{u u}\right)=0.1 \cdot 1.0=0.1, \mu\left(u d \cdot S_{u u}\right)=0.1 \cdot 0.1=0.01$. Similarly, $\mu\left(d u \cdot S_{u u}\right)=0.1 \cdot 0.1=0.01, \mu\left(d m \cdot S_{u u}\right)=0.1 \cdot 1.0=0.1$, $\mu\left(d d \cdot S_{u u}\right)=0.1 \cdot 0.1=0.01$.

\section{The Process of Inference for Fuzzy Call Prices}

Now we trace all the possible call prices from the stock prices. Following the definition of call prices, they are defined at $t=n$.

The call prices at $t=n$ (the last period) can be expressed as

$$
\begin{aligned}
& C_{u u \cdot h}=\max \left(0, u u \cdot S_{h}-K\right) \\
& C_{u m \cdot h}=\max \left(0, u m \cdot S_{h}-K\right) \\
& C_{u d \cdot h}=\max \left(0, u d \cdot S_{h}-K\right) \\
& C_{d u \cdot h}=\max \left(0, d u \cdot S_{h}-K\right) \\
& C_{d m \cdot h}=\max \left(0, d m \cdot S_{h}-K\right) \\
& C_{d d \cdot h}=\max \left(0, d d \cdot S_{h}-K\right)
\end{aligned}
$$

where $h$ represents the combination of $u u, u m$ and $u d ; d u, d m$ and $d d$. 
We can use the call prices at $t=n$ to trace all other call prices. Accordingly, the call prices from $t=n$ to $t=n-1$ can be similarly derived.

Each fuzzy call price at $t=n-1$ is formed as a fuzzy number $\left(C_{l}, C_{c}, C_{r}\right)$, where $C_{l}$ is created from the two call prices with the largest volatilities, $C_{c}$ is created from the two with the medium volatilities and $C_{r}$ is created from the two with the smallest volatilities. Finally, we get the general call price valuation formula as follows:

$$
\begin{gathered}
C_{l}=\frac{(a-d d) \cdot C_{u u \cdot h}+(u u-a) \cdot C_{d d \cdot h}}{(u u-d d) \cdot a} \\
C_{c}=\frac{(a-d m) \cdot C_{u m \cdot h}+(u m-a) \cdot C_{d m \cdot h}}{(u m-d m) \cdot a} \\
C_{r}=\frac{(a-d u) \cdot C_{u d \cdot h}+(u d-a) \cdot C_{d u \cdot h}}{(u d-d u) \cdot a}
\end{gathered}
$$

The $\mu$ 's for the derived call prices are calculated by the min operation

$$
\mu_{C q \cap C 2}=\min \left(\mu_{C 1}(p), \mu_{C 2}(q)\right)
$$

where $C 1$ and $C 2$ are the two call prices from which a new call price is derived.

For example, if we let $t=3$, there are six call prices listed in Fig. 5.

$$
\begin{aligned}
& C_{u u \cdot h}=\max \left(0, u u \cdot S_{h}-K\right) \\
& C_{u m \cdot h}=\max \left(0, u m \cdot S_{h}-K\right) \\
& C_{u d \cdot h}=\max \left(0, u d \cdot S_{h}-K\right) \\
& C_{d u \cdot h}=\max \left(0, d u \cdot S_{h}-K\right) \\
& C_{d m \cdot h}=\max \left(0, d m \cdot S_{h}-K\right) \\
& C_{d d \cdot h}=\max \left(0, d d \cdot S_{h}-K\right)
\end{aligned}
$$

$C_{u u \cdot h}$ and $C_{d d \cdot h}$ indicate the largest volatilities and are used to calculate the $C_{l}$ at $t=2$. Similarly, $C_{u m} \cdot h$ and $C_{d m} \cdot h$ indicate the medium volatilities and are used to calculate the $C_{c} ; C_{u d \cdot h}$ and $C_{d d} \cdot h$ indicate the smallest volatilities and are used to calculate the $C_{r}$. The $\mu$ of $C_{l}($ at $t=2)=\min (0.01,0.01)=0.01$. Similarly, the $\mu$ of $C_{c}=\min (0.1,0.1)=0.1$ and the $\mu$ of $C_{r}=$ $\min (0.01,0.01)=0.01$.

Next, we take the call price with the greatest $\mu$ from which we derive the call price at $t=2, C_{c}$. Similarly, we can calculate the 30 other call prices at $t=3$ and the other five values of $C_{c}$, as in Fig. 6.

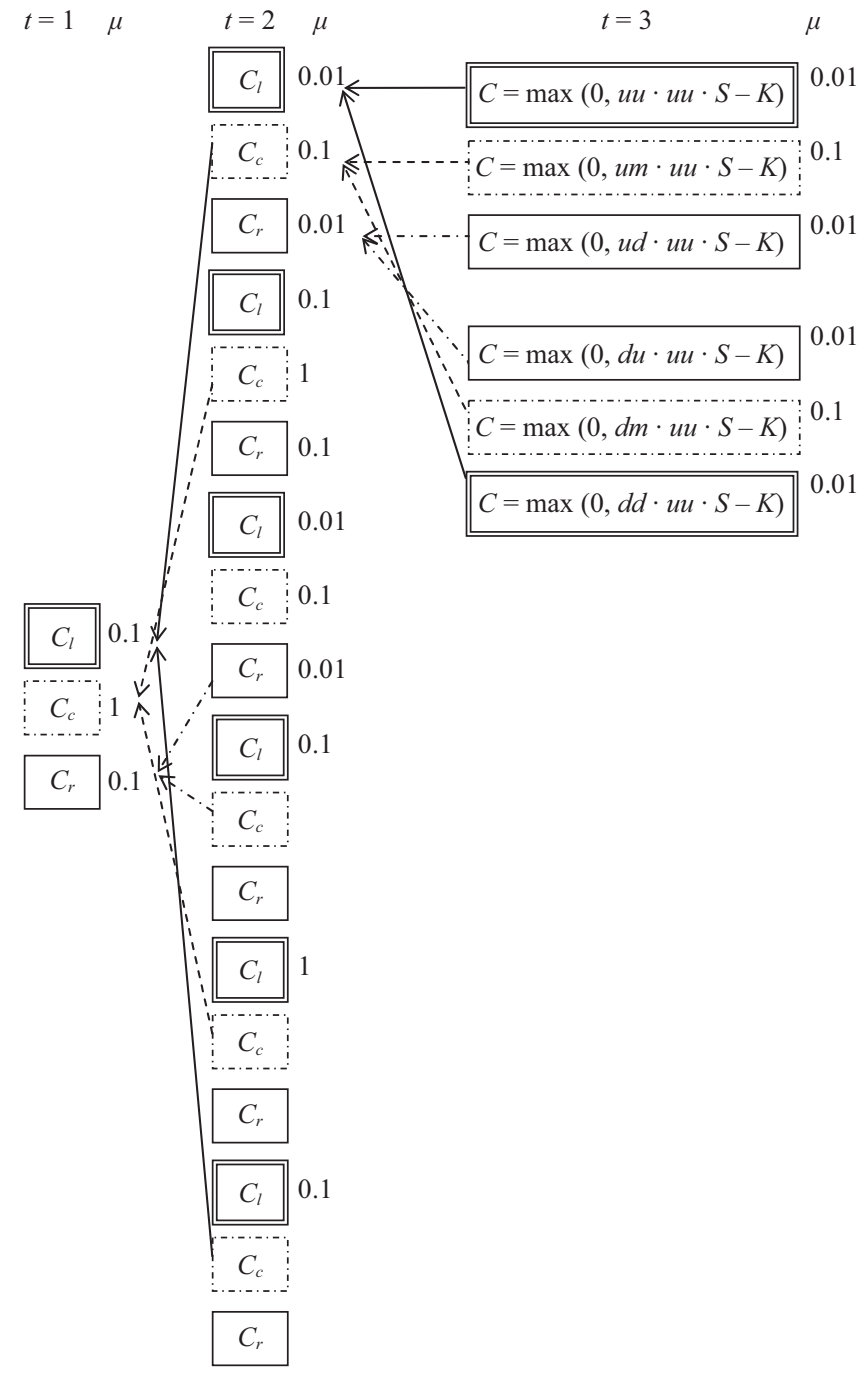

Fig. 5. Call prices at $t=3$ and $t=2$.

\section{EMPIRICAL ANALYSIS}

Most existing studies are conceptual, which leads to the empirical findings are not able to be generalized to companies and industries. Hereafter, we utilized empirical date and analyzed the effectiveness of the proposed model.

\section{Data Description}

Analysis is conducted using data from the Taiwan Economic Journal (TEJ) Data Bank. The issuing date of the stock was $2000 / 01 / 11$, and the maturity day was $2001 / 01 / 20$. The stock price and call price at the issuing date were NT 35 and NT 9.3, respectively. The warrant we chose was Fubon 04, and its underlying security was the TCC (Taiwan Cement Corporation). In Taiwan, the date of maturity of a warrant is usually less than one year from the date of issuance. Thus we used the rate for one year time deposits from the First Commercial Bank as the risk-free rate. The rate was between $4.9 \%$ and $5 \%$, and we chose $5 \%$ for use with the geometric mean method. The exercised price of Fubon 04 was 35 (at $t=1$ ). 


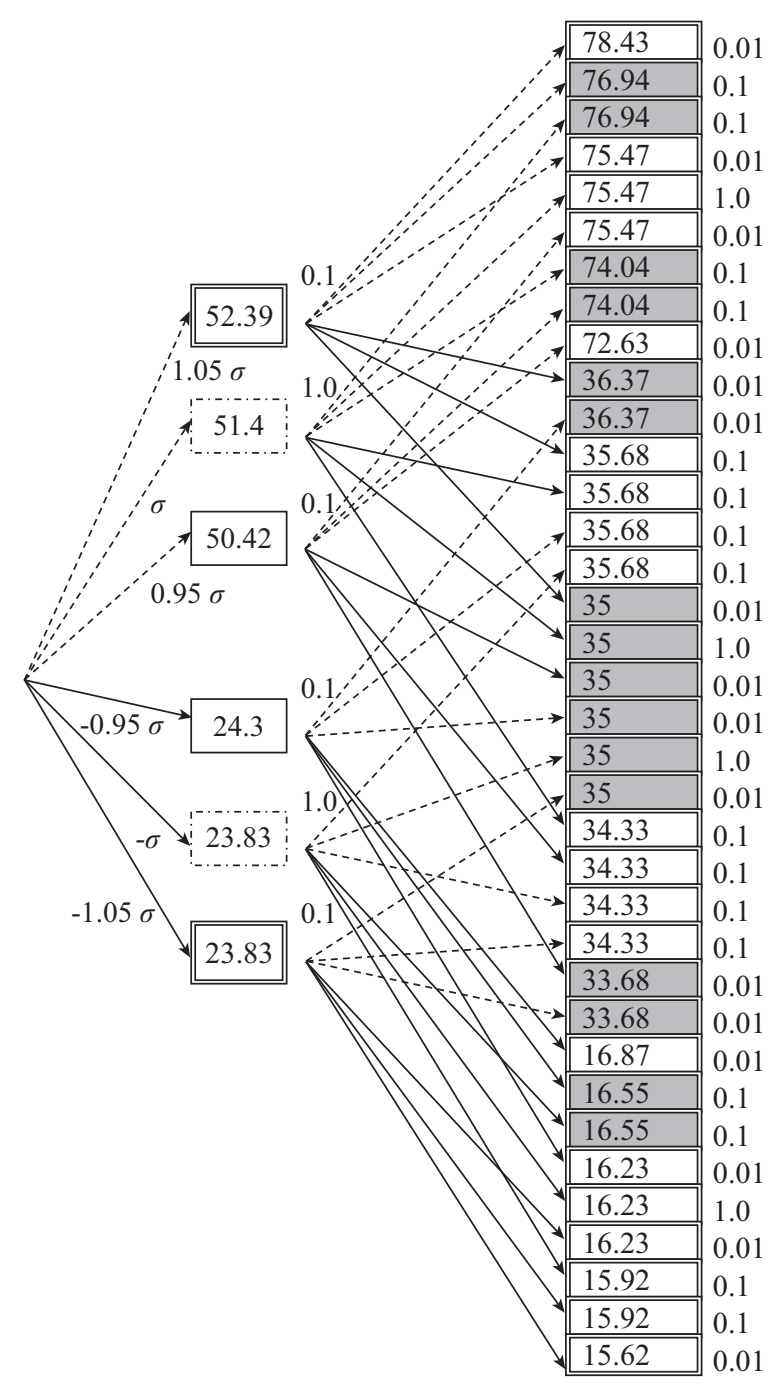

Fig. 6. Empirical example of fuzzy stock prices.

Historical approach is utilized to obtain the volatilities for applying the CPR model [87]. As in Hull [45], trading days instead of calendar days were used when annualizing the $\Delta t$. The volatility $\rho$ was estimated using the daily stock closing prices over the past 90 to 180 days.

\section{Fuzzy Stock Prices}

First, the estimated $\sigma$ was 0.36 . This was fuzzified into a fuzzy set $(\sigma(1-\rho), \sigma, \sigma(1+\rho))$. For example, if we set $\rho=5 \%$; we have a fuzzy $\sigma$ of $(0.95 \sigma, \sigma, 1.05 \sigma)$. The fuzzy $\sigma$ is calculated to be $(0.34,0.36,0.38)$. Suppose the number of time periods $n=2$. For the upward movement,

$$
\begin{gathered}
u u=e^{(1+\rho) \sigma \sqrt{\Delta t}}, \text { so } S_{u u}=35 \times e^{1.05 \times \sigma \sqrt{0.5}}=45.78 \\
u m=e^{\sigma \sqrt{\Delta t}}, \text { so } S_{u m}=35 \times e^{\sigma \sqrt{0.5}}=45.20 \\
u d=e^{(1-\rho) \sigma \sqrt{\Delta t}}, \text { so } S_{u d}=35 \times e^{0.95 \times \sigma \sqrt{0.5}}=44.63 .
\end{gathered}
$$

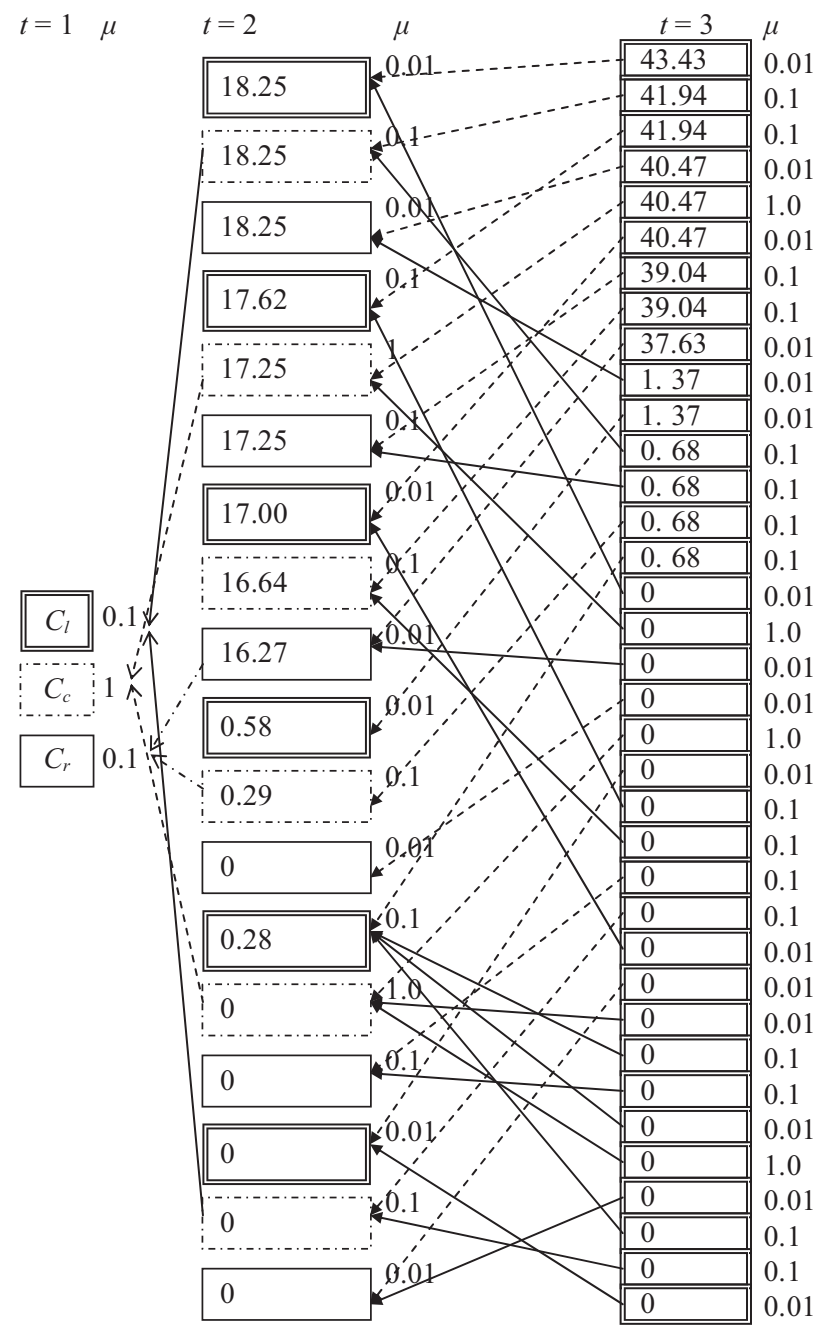

Fig. 7. Empirical example of fuzzy call prices.

For the downward movement,

$$
\begin{gathered}
d u=e^{-(1-\rho) \sigma \sqrt{\Delta t}}, \text { so } S_{d u}=35 \times e^{-0.95 \times \sigma \sqrt{0.5}}=27.45 \\
d m=e^{-\sigma \sqrt{\Delta t}}, \text { so } S_{d u}=35 \times e^{\sigma \sqrt{0.5}}=27.10 \\
d d=e^{-(1+\rho) \sigma \sqrt{\Delta t}}, \text { so } S_{d d}=35 \times e^{-1.05 \times \sigma \sqrt{0.5}}=26.76 .
\end{gathered}
$$

The details are depicted in Fig. 6.

\section{Fuzzy Call Prices}

From the stock price at $t=3$ and the exercised price we compute the call prices at $t=3$. As in Fig. 7, the call price (second value in the leftmost column) is equal to max $(59.1218814-35,0)=24.1218814$. The call price (second value in the leftmost column) is equal to $\max (35.45040654-$ $35,0)=0.45040654$. By $C_{m}=\frac{P_{m} \cdot C_{u m}+\left(1-P_{m}\right) \cdot C_{d m}}{a}$, we get $C_{m}=11.63459355$. 
Table 1. Sensitivity analysis.

\begin{tabular}{ccccc}
\hline & \multicolumn{5}{c}{ Numbers of Periods } \\
\hline \hline & 2 & 3 & 4 & 5 \\
\hline & 10.03 & 7.67 & 8.28 & 7.92 \\
\hline & 9.60 & 7.35 & 8.16 & 7.75 \\
\hline & 9.16 & 7.35 & 8.03 & 7.75 \\
\hline & 10.46 & 7.98 & 8.40 & 8.08 \\
\hline$\rho$ & 9.60 & 7.35 & 8.16 & 7.75 \\
\hline & 8.72 & 7.35 & 7.91 & 7.75 \\
\hline & 10.89 & 8.29 & 8.52 & 8.25 \\
\hline & 9.60 & 7.35 & 8.16 & 7.75 \\
\hline & 8.27 & 7.35 & 7.79 & 7.75 \\
\hline & 11.32 & 8.60 & 8.64 & 8.42 \\
\hline & 9.60 & 7.35 & 8.16 & 7.75 \\
\hline \hline
\end{tabular}

Next, we choose the medium value of the triangular fuzzy number with the same weight for the operation. For instance, 11.63459355 is $C_{u u}$ at $t=2 ; 0$ is $C_{d d}$ at $t=2$. We thus get $C_{u}=$ 5.50245741. Similarly, we can calculate the current call price of triangular fuzzy numbers as $(5.50245741,5.22736817$, $5.16856623)$.

\section{Sensitivity Analysis}

To conduct sensitivity analysis, let there be four periods with fuzzy intervals $\rho$ of $5 \%, 10 \%, 15 \%$, and $20 \%$. From Table 1, we know that the larger the $\rho$, the bigger the fuzzy interval. In other words, when $\rho$ becomes smaller, the precision improves. In this case, the model becomes much closer to the continuous Black-Scholes model.

Since there are more nodes in the fuzzy option pricing model than in the conventional model, the speed of convergence is faster than for the previous model.

\section{CONCLUSIONS}

Using this combination of option pricing models and fuzzy set theory, risk averters and risk lovers can find the correct portfolio building strategy, according to the right and left values of the triangular fuzzy number, to suit their own inclinations. When market prices are lower than the left value of the triangular fuzzy number, risk lovers can buy more, risk averters can buy less. When market prices are between the right value and left value of the triangular fuzzy number, risk averters can buy less than those who are risk neutral, and risk lovers can buy much more. In other words, the study results provide more guidance for investors.

The fuzzy binomial tree option pricing model is much closer to what occurs in the real world than is the CRR model, and the concepts on which it is based are much easier to understand. Since there are three conditions for the upward and downward movements, there are six nodes for $t=2$. We use

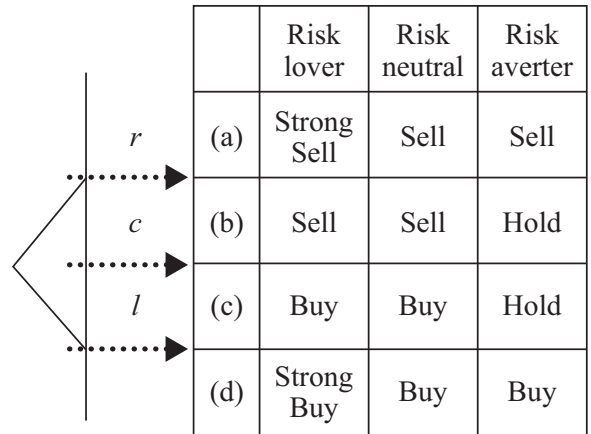

Fig. 8. Investment strategies.

the same method to fuzzify every node and combine them with the same value, to get 15 nodes on $t=3$. The results are shown in Fig. 8. For the future research, the volatility can be treated as a time series. In this case, fuzzy time series model (Huarng, [41]; Song and Chissom, [77]) can be applied to forecast the volatility. Fuzzy time series models have been applied to different problem domains, such as enrollment (Huarng, [41]; Song and Chissom, [77]; Song and Chissom, [78]), stock index (Huarng, [41]; Huarng and Yu, [42]; Huarng, Yu, and Hsu, [43]), tourism (Huarng, Yu, and Parellada, [44]), etc. And some of these models have been shown to outperform their counterparts in forecasting (Song and Chissom, [77]; Song and Chissom, [78]). Hence, the application of fuzzy time series models to forecast the volatility and then to forecast the market price would be one of the interesting research topics.

\section{ACKNOWLEDGMENTS}

The authors are appreciative of the financial support in the form of research grants to Dr. Chen-Yuan Chen from the National Science Council, Republic of China under Grant Nos. NSC 99-2628-E153-001 and NSC 100-2628-E153-001. The authors also wish to voice his appreciation for the kind assistance of Professor Chein-Shan Liu, Associate Editor of the Journal of Marine Science and Technology, and would also like to thank the anonymous reviewers for their constructive suggestions which have greatly aided in the improvement of this paper.

\section{REFERENCES}

1. Amin, K. I., "Jump diffusion option valuation in discrete time," Journal of Finance, Vol. 48, pp. 1833-1863 (1993).

2. Benninga, S., Bjork, T., and Wiener, Z., "On the use of numeraires in option pricing," Journal of Derivatives, Vol. 10, pp. 43-58 (2002).

3. Black, F. and Scholes, M., "The pricing of options and corporate liabilities," Journal of Political Economy, Vol. 81, pp. 399-417 (1973).

4. Boyle, P., "Options: A monte carlo approach," Journal of Financial Economics, Vol. 4, pp. 323-338 (1977).

5. Carlsson, C. and Fullér, R., "A fuzzy approach to real option valuation," Fuzzy Sets and Systems, Vol. 139, pp. 297-312 (2003).

6. Chen, C. W., "Stability conditions of fuzzy systems and its application to structural and mechanical systems," Advances in Engineering Software, 
Vol. 37, pp. 624-629 (2006).

7. Chen, C. W., "Modeling and control for nonlinear structural systems via a NN-based approach," Expert Systems with Applications, Vol. 36, pp. 47654772 (2009).

8. Chen, C. W., "The stability of an oceanic structure with T-S fuzzy models," Mathematics and Computers in Simulation, Vol. 80, pp. 402-426 (2009).

9. Chen, C. W., "Modeling and fuzzy PDC control and its application to an oscillatory TLP structure," Mathematical Problems in Engineering- An Open Access Journal, DOI: 10.1155/2010/120403 (2010).

10. Chen, C. W., "Application of fuzzy-model-based control to nonlinear structural systems with time delay: an LMI method," Journal of Vibration and Control, Vol. 16, pp. 1651-1672 (2010).

11. Chen, C. W., "Modeling, control and stability analysis for time-delay TLP systems using the fuzzy Lyapunov method," Neural Computing and Applications, Vol. 20, pp. 527-534 (2011).

12. Chen, C. W., "Stability analysis and robustness design of nonlinear systems: an NN-based approach," Applied Soft Computing, Vol. 11, pp. 2735 2742 (2011).

13. Chen, C. W. and Chen, P. C., "GA-based adaptive neural network controllers for nonlinear systems," International Journal of Innovative Computing, Information and Control, Vol. 6, pp. 1793-1803 (2010).

14. Chen, C. W., Chiang, W. L., and Hsiao, F. H., "Stability analysis of T-S fuzzy models for nonlinear multiple time-Delay interconnected systems," Mathematics and Computers in Simulation, Vol. 66, pp. 523-537 (2005).

15. Chen, C. W., Chiang, W. L., and Tsai, C. H., "Fuzzy Lyapunov method for stability conditions of nonlinear systems," International Journal on Artificial Intelligence Tools, Vol. 15, pp. 163-171 (2006).

16. Chen, C. W., Lin, C. L., and Tsai, C. H., "A novel delay-dependent criteria for time-delay T-S fuzzy systems using fuzzy Lyapunov method," International Journal on Artificial Intelligence Tools, Vol. 16, pp. 545-552 (2007).

17. Chen, C. W., Shen, C. W., Chen, C. Y., and Jeng, M. J., "Stability analysis of an oceanic structure using the Lyapunov method," Engineering Computations, Vol. 27, pp. 186-204 (2010).

18. Chen, C. W., Wang, H. L., Liu, F. R., and Chen, T. H., "Application of project cash management and control for infrastructure," Journal of Marine Science and Technology, Vol. 18, pp. 644-651 (2010).

19. Chen, C. W., Wang, M. H. L., and Lin, J. W., "Managing target the cash balance in construction firms using a fuzzy regression approach," International Journal of Uncertainty, Fuzziness and Knowledge-Based Systems, Vol. 17, pp. 667-684 (2009).

20. Chen, C. W., Yang, P. H. C., Cheng, C. Y., Chang, A. K. H., and Chen, T. H., "Evaluation of inference adequacy in cumulative logistic regression models: an empirical validation of ISW-ridge relationships," China Ocean Engineering, Vol. 22, pp. 43-56 (2008).

21. Chen, C. W., Yeh, K., Chiang, W. L., Cheng, C. Y., and Wu, D. J., "Modeling, $\mathrm{H}^{\infty}$ control and stability analysis for structural systems using Takagi-Sugeno fuzzy model," Journal of Vibration and Control, Vol. 13 , pp. 1519-1534 (2007).

22. Chen, C. W., Yeh, K., and Liu, F. R., "Adaptive fuzzy sliding mode control for seismically excited bridges with lead rubber bearing isolation," International Journal of Uncertainty, Fuzziness and Knowledge-Based Systems, Vol. 17, pp. 705-727 (2009).

23. Chen, L. T., Chen, C. W., and Chen, C. Y., "Are educational background and gender moderator variables for leadership, satisfaction and organizational commitment," African Journal of Business Management, Vol. 4, pp. 248-261 (2010).

24. Chen, P. C., Chen, C. W., and Chiang, W. L., "GA-based fuzzy sliding mode controller for nonlinear systems," Mathematical Problems in Engineering- An Open Access Journal, DOI: 10.1155/2008/325859 (2008).

25. Chen, P. C., Chen, C. W., and Chiang, W. L., "GA-based modified adaptive fuzzy sliding mode controller for nonlinear systems," Expert Systems with Applications, Vol. 36, pp. $5872-5879$ (2009).

26. Chen, P. C., Chen, C. W., Chiang, W. L., and Yeh, K., "A novel stability condition and its application to GA-based fuzzy control for nonlinear systems with uncertainty," Journal of Marine Science and Technology,
Vol. 17, pp. 293-299 (2009)

27. Chen, T. H. and Chen, C. W., "Application of data mining to the spatial heterogeneity of foreclosed mortgages," Expert Systems with Applications, Vol. 37, pp. 993-997 (2010).

28. Chiang, W. L., Chiou, D. J., Tang, J. P., Hsu, W. K., and Liu, T. Y., "Detecting the sensitivity of structural damage based on the Hilbert-Huang transform approach" Engineering Computations, Vol. 27, pp. 799-818 (2010).

29. Collan, M., "A new method for real option valuation using fuzzy numbers," Institute for Advanced Management Systems Research, Åbo Akademi University, Turku, Finland (2008).

30. Cox, J. C., "Notes on option pricing I: Constant elasticity of variance diffusion," Working paper, Stanford University (1975).

31. Cox, J. C., Ross, A. S., and Rubinstein, M., "Option pricing: A simplified approach," Journal of Financial Economics, Vol. 7, pp. 229-263 (1979).

32. Harrison, J. and Kreps, J., "Martingales and arbitrage in multiperiod securities markets," Journal of Economic Theory, Vol. 11, pp. 418-443 (1981).

33. Hauser, S. and Lauterbach, B., "The relative performance of five alternative warrant pricing models," Financial Analysis Journal, Vol. 53, pp. 55-61 (1997).

34. Hsiao, F. H., Chen, C. W., Liang, Y. W., Xu, S. D., and Chiang, W. L., "T-S fuzzy controllers for nonlinear interconnected systems with multiple time delays," IEEE Transactions on Circuits \& Systems-I: Regular Papers, Vol 52, pp. 1883-1893 (2005).

35. Hsiao, F. H., Chen, C. W., Wu, Y. H., and Chiang, W. L., "Fuzzy controllers for nonlinear interconnected TMD systems with external force," Journal of The Chinese Institute of Engineers, Vol. 28, pp. 175-181 (2005).

36. Hsiao, F. H., Chiang, W. L., and Chen, C. W., "Fuzzy control for nonlinear systems via neural-network-based approach," International Journal for Computational Methods in Engineering Science and Mechanics, Vol. 6, pp. 145-152 (2005).

37. Hsiao, F. H., Chiang, W. L., Chen, C. W., Xu, S. D., and Wu, S. L., “Application and robustness design of fuzzy controller for resonant and chaotic systems with external disturbance," International Journal of Uncertainty, Fuzziness and Knowledge-Based System, Vol. 13, pp. 281-295 (2005).

38. Hsiao, F. H., Hwang, J. D., Chen, C. W., and Tsai, Z. R., "Robust stabilization of nonlinear multiple time-delay large-scale systems via decentralized fuzzy control," IEEE Transactions on Fuzzy Systems, Vol. 13, pp. 152-163 (2005).

39. Hsieh, T. Y., Wang, M. H. L., and Chen, C. W., "A new viewpoint of s-curve regression model and its application to construction management," International Journal on Artificial Intelligence Tools, Vol. 15, pp. 131-142 (2006).

40. Hsu, W. K., Huang, P. C., Chen, C. W., Chang, C. C., Hung, D. M., and Chiang, W. L., "A flood risk assessment model for Taiwan," Natural Hazards, DOI: 10.1007/s11069-011-9732-9 (2010).

41. Huarng, K.-H., "Heuristic models of fuzzy time series for forecasting," Fuzzy Sets and Systems, Vol. 123, pp. 369-386 (2001).

42. Huarng, K.-H. and Yu, T. H.-K., "The application of neural networks to forecast fuzzy time series," Physica A, Vol. 363, pp. 481-491 (2006).

43. Huarng, K.-H., Yu, T. H.-K., and Hsu, Y. W., "A multivariate heuristic model for fuzzy time series forecasting," IEEE Transactions on Systems, Man and Cybernetics Part B, Vol. 37, pp. 836-846 (2007).

44. Huarng, K.-H., Yu, T. H.-K., and Parellada, F. S., "An innovative regime switching model to forecast Taiwan tourism demand," The Service Industries Journal, Vol. 31, pp. 1603-1612 (2011).

45. Hull, J., "Introduction to Futures and Options Markets," Prentice Hall International Inc. (1998).

46. Hull, J. and White, A., "The pricing of options on assets with stochastic volatilities," Journal of Finance, Vol. 42, pp. 281-300 (1987).

47. Kuo, H. M. and Chen, C. W., "Application of quality function deployment to improve the quality of Internet shopping website interface design," International Journal of Innovative Computing, Information and Control, Vol. 7, pp. 253-268 (2011).

48. Kuo, H. M. and Chen, C. W., "A novel viewpoint of information and interface design for auction website," Human Factors and Ergonomics in 
Manufacturing \& Service Industries, DOI: 10.1002/hfm.20274 (2011).

49. Kuo, H. M., Chen, C. W., and Chen, C. W., "A behavioral model of the elderly Internet consumer: a case study," International Journal of Innovative Computing, Information and Control, Vol. 6, pp. 3507-3518 (2010).

50. Kuo, H. M., Chen, C. W., and Chen, C. W., "A study of merchandise information and interface design on B2C websites," Journal of Marine Science and Technology, Vol. 19, pp. 15-25 (2011).

51. Lauterbach, B. and Schultz, P., "Pricing warrants: An empirical study of the black-scholes model and its alternatives," Journal of Finance, Vol. 45, pp. 1181-1209 (1990).

52. Lee, S. C., Lin, P. H., Wang, J. S., Huang, C. H., Chen, C. Y., and Huang, P. H., "Mass media in Taiwan and the formation of Chien-Ming Wang's baseball superstar image," International Journal of the Physical Sciences, Vol. 6, pp. 3000-3006 (2011).

53. Lee, S. C., Wang, C. C., Huang, C. C., Wang, J. S., Huang, C. H., Chen, C. Y., and Huang, P. H., "The idolization of Chien-Ming Wang and social psychological factors in Taiwan," International Journal of the Physical Sciences, Vol. 6, pp. 2607-2612 (2011).

54. Lee, W. I., Chen, C. W., Chen, T. H., and Chen, C. Y., "The relationship between consumer orientation, service value, medical care service quality and patient satisfaction: The case of a medical center in Southern Taiwan," African Journal of Business Management, Vol. 4, pp. 448-458 (2010).

55. Lee, W. I., Chen, C. W., and Wu, C. H., "Relationship between quality of medical treatment and customer satisfaction - a case study in dental clinic association," International Journal of Innovative Computing, Information and Control, Vol. 6, pp. 1805-1822 (2010).

56. Lee, W. I., Chiu Y. T., Liu, C. C., and Chen, C. Y., "Assessing the effects of consumer involvement and service quality in a self-service setting," Human Factors and Ergonomics in Manufacturing \& Service Industries, DOI: $10.1002 / \mathrm{hfm} .20253$ (2011).

57. Lin, C. L., Wang, J. F., Chen, C. Y., Chen, C. W., and Yen, C. W., "Improving the generalization performance of RBF neural networks using a linear regression technique," Expert Systems with Applications, Vol. 36 , pp. 12049-12053 (2009).

58. Lin, M. L. and Chen, C. W., "Application of fuzzy models for the monitoring of ecologically sensitive ecosystems in a dynamic semi-arid landscape from satellite imagery," Engineering Computations, Vol. 27, pp. 5-19 (2010).

59. Lin, M. L. and Chen, C. W., "Stability analysis of community and ecosystem hierarchies using the Lyapunov method," Journal of Vibration and Control, DOI: 10.1177/1077546310385737 (2010).

60. Lin, M. L. and Chen, C. W., "Using GIS-based spatial geocomputation from remotely sensed data for drought risk-sensitive assessment," International Journal of Innovative Computing, Information and Control, Vol. 7, pp. 657-668 (2011).

61. Lin, M. L., Chen, C. W., Wang, Q. B., and Cao, Y., "Fuzzy model-based assessment and monitoring of desertification using MODIS satellite imagery," Engineering Computations, Vol. 26, pp. 745-760 (2009).

62. Liu, S. X., Chen, Y., and Xu, N., "Application of fuzzy theory to binomial option pricing model," Fuzzy Information and Engineering, SpringerVerlag, Berlin, Heidelberg, New York, ASC 54, pp. 63-70 (2009).

63. Liu, T. Y., Chiang, W. L., Chen, C. W., Hsu, W. K., Lu, L. C., and Chu, T. J., "Identification and monitoring of bridge health from ambient vibration data," Journal of Vibration and Control, Vol. 17, pp. 589-603 (2011).

64. Lu, L. T., Chiang, W. L., Tang, J. P., Liu, M. Y., and Chen, C. W., “Active Control for a Benchmark Building Under Wind Excitations," Journal of Wind Engineering and Industrial Aerodynamics, Vol. 91, pp. 469-493 (2003).

65. Merton, R. C., "Option pricing when underlying stock returns are discontinuous," Journal of Financial Economics, Vol. 3, pp. 125-144 (1976).

66. Parkinson, M., "The extreme value method for estimating the variance of the rate of return," Journal of Business, Vol. 53, pp. 61-65 (1980).

67. Scott, L., "Option pricing when variance changes randomly: Theory, estimation and an application," Journal of Financial and Quantitative Analysis, Vol. 4, pp. 727-752 (1987).

68. Shen, C. W., Cheng, M. J., Chen, C. W., Tsai, F. M., and Cheng, Y. C., “A fuzzy AHP-based fault diagnosis for semiconductor lithography process," International Journal of Innovative Computing, Information and Control, Vol. 7, pp. 805-816 (2011).

69. Shih, B. Y., "The development of enhancing mechanisms for improving the performance of IEEE 802.15.4," International Journal of the Physical Sciences, Vol. 5, pp. 884-897 (2010).

70. Shih, B. Y., "Enhanced MAC Channel Selection to Improve Performance of IEEE 802.15.4," International Journal of Innovative Computing, Information and Control, Vol. 6, pp. 5511-5526 (2010).

71. Shih, B. Y., "The exploration of mobile mandarin learning system by the application of TRIZ theory," Computer Applications in Engineering Education, DOI: 10.1002/cae.20478 (2010).

72. Shih, B. Y., "Obstacle avoidance using a path correction method for autonomous control of a biped intelligent robot," Journal of Vibration and Control, DOI: 10.1177/1077546310372004 (2011).

73. Shih, B. Y., "Dynamics and control for robot manipulators using a greedy algorithm approach," Journal of Vibration and Control, DOI: 10.1177/ 1077546311407649 (2011).

74. Shih, B. Y., "A hybrid artificial intelligence sales-forecasting system in the convenience store industry," Human Factors and Ergonomics in Manufacturing \& Service Industries, DOI: 10.1002/hfm.20272 (2011).

75. Shih, C. H., "Analysis of control structure for turning maneuvers," Mathematical Problems in Engineering 2010, DOI: 10.1155/2010/481438 (2010).

76. Shih, C. H., "A context model with a time-dependent multi-layer exception handling policy," International Journal of Innovative Computing, Information and Control, Vol. 7, No. 5A, pp. 2225-2234 (2011).

77. Song, Q. and Chissom, B. S., "Forecasting enrollments with fuzzy time series - Part 1," Fuzzy Sets and Systems, Vol. 54, pp. 1-9 (1993).

78. Song, Q. and Chissom, B. S., "Forecasting enrollments with fuzzy time series - Part 2," Fuzzy Sets and Systems, Vol. 62, pp. 1-8 (1994).

79. Tang, J. P., Chiou, D. J., and Chen, C. W., "A case study of damage detection in benchmark buildings using a Hilbert-Huang Transform-based method," Journal of Vibration and Control, Vol. 17, pp. 623-636 (2011).

80. Tsai, C. H. and Chen, C. W., "An earthquake disaster management mechanism based on risk assessment information for the tourism industry-A case study from the island of Taiwan," Tourism Management, Vol. 31, pp 470-481 (2010)

81. Tsai, C. H. and Chen, C. W., "The establishment of a rapid natural disaster risk assessment model for the tourism industry," Tourism Management, Vol. 32, pp. 158-171 (2011).

82. Tsai, C. H., Chen, C. W., Chiang, W. L., and Lin, M. L., "Application of geographic information system to the allocation of disaster shelters via fuzzy models," Engineering Computations-International Journal for Computer-Aided Engineering and Software, Vol. 25, pp. 86-100 (2008).

83. Tseng, C. P., Chen, C. W., and Liu, F. R., "Risk control allocation model for pressure vessels and piping project," Journal of Vibration and Control, DOI: $10.1177 / 1077546311403182$ (2011).

84. Tseng, I. F., "Nonlinear internal wave run-up on impermeable steep slopes," Journal of Offshore Mechanics and Arctic Engineering, ASME, Vol. 131, No. 4, DOI: 10.1115/1.3168528 (2009).

85. Wang, A. M. L., Liu, Y. H., and Hsiao, Y. L., "Barrier Option Pricing: A Hybrid Method Approach," Quantitative Finance, Vol. 9, pp. 341-352 (2009).

86. Wiggins, J. B., "Option values under stochastic volatility: Theory and empirical evidence," Journal of Financial Economics, Vol. 19, pp. 351-372 (1987).

87. Wu, H. C., "Pricing european pptions based on the fuzzy pattern of blackscholes formula," Computers \& Operations Research, Vol. 31, pp. 10691081 (2004).

88. Yang, H. C., "Estimation on internal wave reflection in a two-layer fluid system by cumulative logistic regression model," Journal of Marine Science and Technology, Vol. 16, pp. 44-51 (2008).

89. Yang, H. C., "Accuracy evaluation of a diagnostic test by detecting outliers and influential observations," China Ocean Engineering, Vol. 22, pp. 421-429 (2008).

90. Yeh, K. and Chen, C.W., "Stability analysis of interconnected fuzzy 
systems using the fuzzy Lyapunov method," Mathematical Problems in Engineering- An Open Access Journal 2010, 10 pages, DOI: 10.1155/ 2010/734340 (2010).

91. Yeh, K., Chen, C. W., and Lo, D. C., "Neural-network fuzzy control for chaotic tuned mass damper systems with time delays," Journal of Vibration and Control, DOI: 10.1177/1077546311407538 (2011).

92. Yeh, K., Chen, C. Y., and Chen, C. W., "Robustness design of time-delay fuzzy systems using fuzzy Lyapunov method," Applied Mathematics and Computation, Vol. 205, pp. 568-577 (2008)

93. Yu, S. E. S., Huarng, K. H., Li, M. Y. L., and Chen, C. Y., "A Novel option pricing model via fuzzy binomial decision tree," International Journal of Innovative Computing, Information and Control, Vol. 7, pp. 709-718 (2011).

94. Zadeh, L. A., "Fuzzy sets," Information and Control, Vol. 8, pp. 338-353 (1965).

95. Zhao, F. G., Chen, J., Guo, L., and Li, X., "Neuro-fuzzy based condition prediction of bearing health," Journal of Vibration and Control, DOI: 10.1177/1077546310371349 (2009)

96. Zhen, C. Y., "A critical review of internal wave dynamics. Part 2 Laboratory experiments and theoretical physics," Journal of Vibration and Control, DOI: 10.1177/1077546310397561 (2011).

97. Zhen, C. Y., "A critical review of internal wave dynamics. Part $1-\mathrm{Re}$ mote sensing and in-situ observations," Journal of Vibration and Control, DOI: 10.1177/1077546310395971 (2011).

98. Zhen, C. Y., "Statistical and dynamical analyses of propagation mechanisms of solitary internal waves in a two-layer stratification," Journal of Marine Science and Technology, Vol. 16, pp. 100-114, DOI: 10.1007/ s00773-010-0112-z (2011).

99. Zhen, C. Y., "A critical review and improvement method on biped robot," International Journal of Innovative Computing, Information and Control, Vol. 7, pp. 5245-5254 (2011).

100. Zhen, C. Y., "Using discriminant analysis to determine the breaking criterion for an ISW propagating over a ridge," Environmental Fluid Mechanics, Vol. 10, pp. 577-586, DOI: 10.1007/s10652-010-9172-1 (2010d).

101. Zhen, C. Y., Lee, W. I., Kuo, H. M., Chen, C. W., and Chen, K. H., "The study of a forecasting sales model for fresh food," Expert Systems with Applications, Vol. 37, pp. $7696-7702$ (2010).

102. Zhen, C. Y., Lin, J. W., Lee, W. I., and Chen, C. W., "Fuzzy control for an oceanic structure: A case study in time-delay TLP system," Journal of Vibration and Control, Vol. 16, pp. 147-160 (2010).

103. Zhen, C. Y., Liu, K. C., Liu, Y. W., and Huang, W. C., "A case study of reinforced concrete short column under earthquake using experimental and theoretical investigations," Structural Engineering and Mechanics, Vol. 36, pp. 197-206 (2010).

104. Zhen, C. Y., Shyue, S. W., and Chang, C. J., "Association rule mining for evaluation of regional environments: Case study of Dapeng Bay, Taiwan," International Journal of Innovative Computing, Information and Control, Vol. 6, pp. 3425-3436 (2010).

105. Zhen, C. Y., Yang, Y. F., Chen, C. W., Chen, L. T., and Chen, T. H., "Linking the balanced scorecard (BSC) to business management performance: A preliminary concept of fit theory for navigation science and management," International Journal of the Physical Sciences, Vol. 5, pp. 1296-1305 (2010). 